\title{
Tratamento da úlcera escleral pós-cirurgia de pterígio e betaterapia por enxerto de esclera autóloga de espessura parcial
}

\author{
Partial thickness autologus scleral graft for treating scleral \\ ulcers following pterygium excision and betatherapy
}

Eurípedes da Mota Moura', Marcos Volpini², Guilherme Afonso Garcia Moura ${ }^{3}$

\section{ResUMo}

Objetivo: Avaliação dos resultados da utilização de enxerto de espessura parcial de esclera autóloga para o tratamento das úlceras esclerais profundas, como complicação tardia da exérese de pterígio associada à betaterapia. Métodos: Foram tratados doze olhos de doze pacientes, nove femininos e três masculinos, com idade variando entre 48 e 82 anos, média 65,2 anos. Resultados: Houve boa integração do enxerto em todos os casos, com resultado funcional e cosmético favorável e sem complicações. Conclusão: Várias técnicas de enxertia tem sido propostas para o tratamento da úlcera escleral: esclera e dura-máter homólogas, derme, cartilagem auricular e periósteo autólogos. No entanto, o procedimento com esclera autóloga apresenta reais vantagens em relaçâo aos enxertos empregados anteriormente. Não há referências na literatura quanto ao emprego de enxerto de esclera autóloga de espessura parcial para o tratamento da úlcera escleral.

Descritores: Esclera/transplantation;Transplante autólogo; Pterígio/cirurgia; Pterígio/radioterapia;Efeitos de radiação

\begin{abstract}
Objeticve: The authors describes a surgical technique that utilizes autologus delaminated scleral graft for the management of deep scleral ulcers. Methods: In this technique that were perfomed in 12 eyes of 12 patients, 9 female, 3 male, age from 48 to 82 years, mean age 65.2 years. Results: Occurred good integration of the grafting in all cases without any complications. Conclusion: Many techniques have been proposed for the management of scleral ulcers: sclera and dura-mater, autologus derme, auricular cartilage and autologus periosteum. There is no reference in relation to autologus scleral grafting with partial thickness for the treatment of scleral ulcers, as proposed in this study.

Keywords: Sclera/transplantation;Transplantation, autologous; Pterygium/surgery; Pterygium/radiotherapy; Radiation effects
\end{abstract}

\footnotetext{
${ }^{1}$ Faculdade de Medicina, Universidade de São Paulo - USP - São Paulo (SP), Brasil;

${ }^{2}$ Hospital Sírio Libanês. São Paulo (SP), Brasil;

${ }^{3}$ Hospital CEMA. São Paulo (SP), Brasil.

Trabalho realizado no Hospital Sírio Libanês, São Paulo (SP), Brasil.
}

Os autores declaram inexistir conflitos de interesse

Recebido para publicação em 13/01/2010 - Aceito para publicação em 02/03/2012 


\section{INTRODUÇÁO}

A exérese do pterígio é um procedimento cirúrgico comum em nosso meio. $\mathrm{O}$ índice de revascularizaçáo e recidiva após a simples excisão pode atingir $69 \%$, especialmente em ambientes quentes, secos e com alta exposição a radiação ultravioleta. ${ }^{(1)}$ A betaterapia tem sido utilizada como terapêutica complementar no pós-operatório para reduzir a sua recorrência. ${ }^{(2)}$ A recidiva foi de $16 \%$ quando a betaterapia era iniciada até 24 horas após a exérese do pterígio. A utilização desta radiação no pós-operatório, tem o objetivo de reduzir a revascularização e contribue para que este procedimento não seja isento de complicações. $^{(3)}$

As seguintes sequelas oculares estão associadas à betaterapia: telangiectasia, queratinizaçáo conjuntival, conjuntivite crônica, simbléfaro, ptose palpebral, atrofia de íris, catarata, corneoesclerite, úlcera ou necrose corneoescleral. ${ }^{(1)}$ As úlceras esclerais profundas delineiam o tecido uveal subjacente (Figura 1), predispondo o indivíduo a um risco de perfuração ocular, uveíte e endoftalmite. Estas condições podem levar à perda da visão, motivo pelo qual, esta complicação deve ser tratada cirurgicamente. ${ }^{(4)}$

No presente estudo, descreve-se a técnica de enxertia de esclera autóloga no tratamento da úlcera escleral profunda com exposição uveal, secundária a exérese de pterígio e betaterapia com o objetivo de restabelecer a espessura da parede do bulbo ocular.

\section{Métodos}

No período de janeiro de 1998 a dezembro de 2006, 12 olhos de 12 pacientes, nove do sexo feminino e três do masculino, com idade variando de 48 a 82 anos, média de 65,2 anos, portadores de úlceras esclerais profundas com exposição uveal localizadas no setor nasal, decorrentes de exérese de pterígio e betaterapia, foram submetidos a enxertia de esclera delaminada autóloga. Os casos foram operados no Hospital Sírio Libanês em São Paulo e na Clínica de Olhos de um dos autores (EMM).

A técnica cirúrgica descrita foi baseada na ressecção escleral lamelar proposta por Blaskowicz em 1911 para o tratamento da alta miopia ${ }^{(5)}$ e foi realizada com lupa cirúrgica. A anestesia é local, peribulbar com cloridrato de lidocaína $2.0 \%$ sem vasoconstrictor, associada à infiltração subtenoniana no quadrante nasal superior e na região da úlcera escleral. Mede-se com auxí- lio do compasso a área ulcerada (Figura 2). Faz-se a divulsão da conjuntiva, separando-a do leito escleral com tesoura, escarifica a margem da úlcera com bisturi de lâmina 15 , e eventual remoção de placas de calcificação quando presentes. Efetua-se a cauterização com pinça bipolar.

O enxerto escleral de espessura parcial foi retirado do quadrante súpero-nasal anteriormente à inserção dos músculos reto superior e medial, com forma compatível, mas com área de $0,5 \mathrm{~mm}$ maior que a da úlcera. $\mathrm{O}$ enxerto foi suturado com fio vicril 7-0 com pontos simples e separados. (Figuras 3 e 4). Recobre-se a área do enxerto com conjuntiva através de um retalho de deslizamento. Curativo oclusivo nas primeiras 24 horas e colírio de antibiótico e corticoesteróide 4 vezes ao dia durante 2 semanas.

\section{Resultados}

Todos os pacientes apresentaram boa integração do enxerto escleral, não apresentando qualquer reabsorção. Não se observou desnível na região do limbo corneal e os pacientes não apresentaram queixa de epífora, fotofobia ou sensação de corpo estranho no pósoperatório tardio. Em todos os casos a mobilização da conjuntiva adjacente permitiu um adequado recobrimento do tecido transplantado sobre a úlcera escleral. O período de seguimento tardio ainda permitiu observar que:

a) A área doadora, no quadrante nasal superior, ficou com uma coloração levemente mais escura que a vizinha, mas não ocorreu qualquer sinal de estafiloma;

b) $\mathrm{O}$ enxerto escleral aparentemente não apresentou retração ou adelgaçamento durante o período de seguimento;

c) Acuidade visual, tonometria e biomicroscopia do segmento anterior mantiveram-se inalteradas após a cirurgia;

d) Com a utilização de um enxerto de espessura parcial, não se observou após a cicatrização nenhuma elevação ou desnivelamento em relação a esclera e córnea. O filme lacrimal manteve-se bem distribuído no limbo próximo ao enxerto (Figura 5).

\section{DısCUSSÃO}

São várias as técnicas propostas para o tratamento cirúrgico do pterígio: transposição, excisão simples, deixando a esclera nua, excisão com rotação de retalho conjuntival, enxerto de membrana amniótica ou 


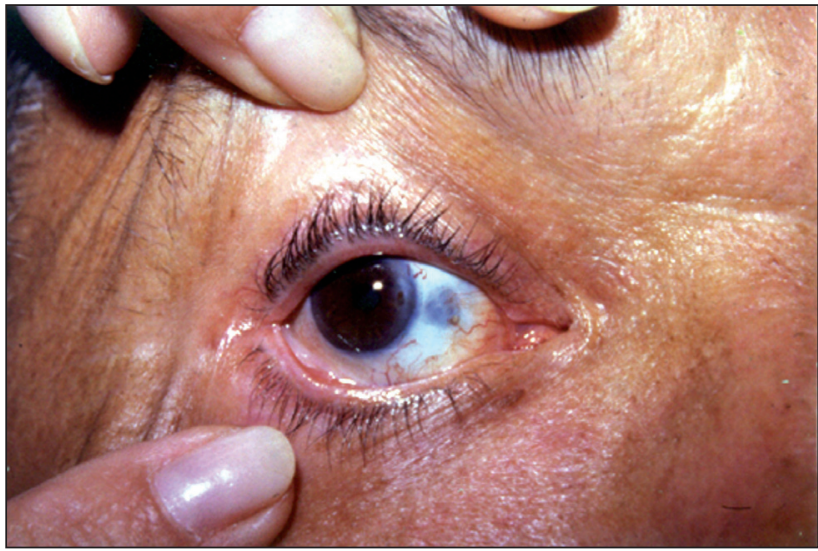

Figura 1: Úlcera escleral pós-exérese de pterígio e betaterapia

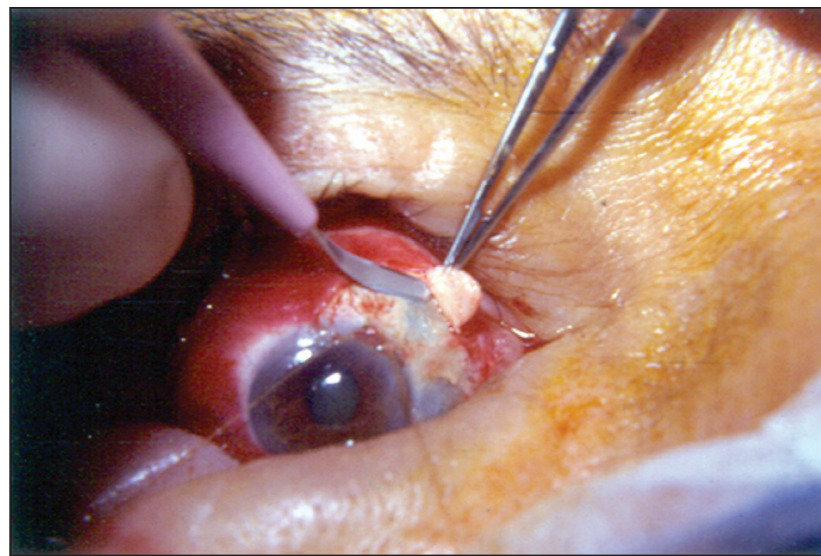

Figura 3: Delaminação do enxerto escleral

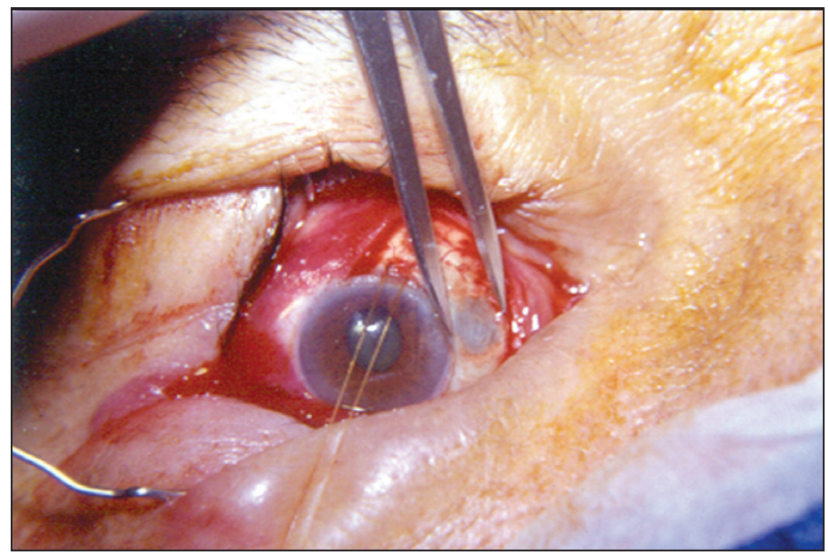

Figura 2: Medida da lesão escleral

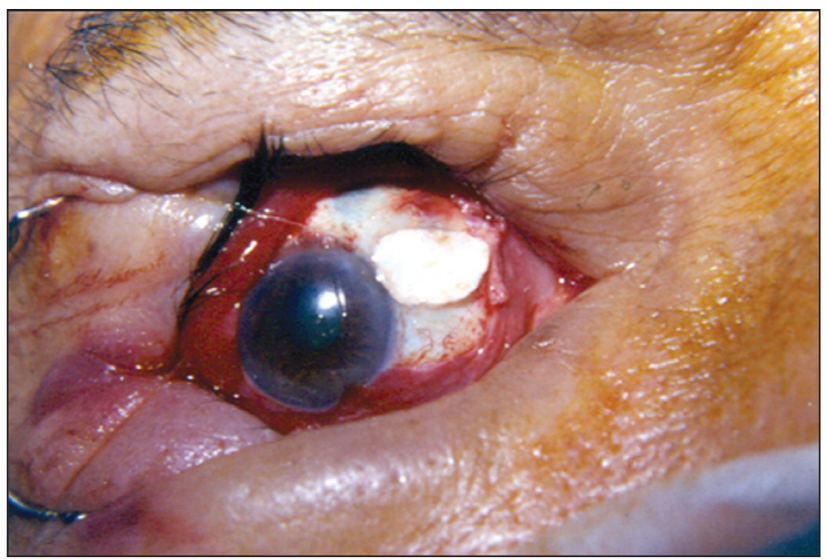

Figura 4: Enxerto no leito receptor para ser suturado

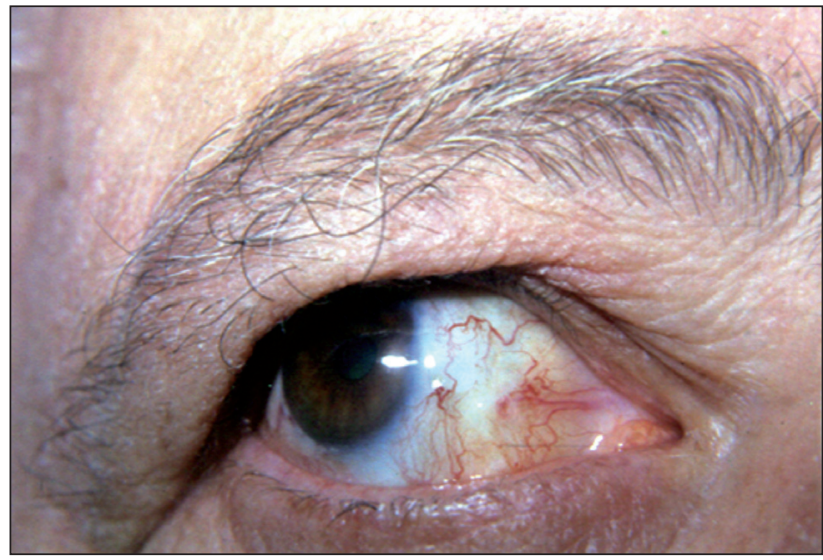

Figura 5: Pós-operatório tardio 
conjuntiva autóloga. As técnicas disponíveis para o tratamento do pterígio devem ser avaliadas segundo dois critérios: ausência de complicações que comprometam a visão e redução da frequência de recidivas.

O enxerto autólogo de conjuntiva tem sido utilizado desde 1985 no tratamento do pterígio com o objetivo de reduzir as taxas de recidiva. ${ }^{(6)}$ Esta técnica consiste no enxerto de conjuntiva bulbar incluindo a região do limbo corneal obtido do setor superior do mesmo olho; remove-se o pterígio e transplanta-se a conjuntiva para a área receptora. O enxerto deve ser suturado mantendo a margem limbar na periferia da córnea. Kenyon et al. observaram uma taxa de recorrência de 5,3\% em pterígios recidivados ou avançados utilizando esta técnica. ${ }^{(7)}$ As complicações decorrentes do enxerto de conjuntiva tais como: granuloma, cisto conjuntival, infecção ou falência do transplante podem ocorrer.

Estudos demonstram que pacientes submetidos à exérese de pterígio associada à betaterapia, com seguimento por mais de 10 anos desenvolveram escleromalacia em $10 \%$ e adegalçamento escleral grave em $4,5 \%$. A ocorrência de necrose escleral pelo uso de betaterapia, revela o provável desconhecimento da dosagem segura e do esquema de fracionamento no pós-operatório. A esclera posterior parece ser mais resistente à radioterapia, enquanto a anterior é mais susceptível à combinação de cirurgia e betaterapia. ${ }^{(5)} \mathrm{Ou}-$ tros fatores que poderiam contribuir para esta complicação são: cauterização excessiva, que provocaria uma retração tecidual, deficiência de filme lacrimal comprometendo a lubrificação local, ausência de conjuntiva pela técnica cirúrgica da esclera nua e possível descalibração dos aparelhos de irradiação. ${ }^{(7,8)}$

Clinicamente as úlceras esclerais podem ser classificadas em três grupos: a) superficial, caracterizada por exposição das camadas da esclera com uma área de conjuntiva avascular, ulceração rasa com comprometimento de menos de um terço de espessura escleral; b) Moderada, caracterizada pelo envolvimento de um a dois terços da espessura escleral, com base frequentemente constituída por uma fina camada de fibras esclerais sobre o tecido uveal subjacente; podem ser encontradas também placas de calcificação no seu leito. ${ }^{(1)}$ Esta lesão pode ser observada, em geral muitos anos após o tratamento inicial; este período pode variar de 9 a 30 anos. ${ }^{(5)}$ O tratamento cirúrgico com enxertos somente está indicado nos casos de úlceras esclerais profundas.

A técnica cirúrgica indicada para a úlcera escleral profunda é um reforço tecidual às custas de um enxerto. Várias modalidades de tratamento foram propostas para a correção desta complicação tardia: córnea e esclera homólogas, dura-mater, derme de espessura parcial, pericárdio humano processado, cartilagem auricular e periósteo autógeno. ${ }^{(10-17)}$

A esclera e córnea homólogas têm a vantagem da disponibilidade em Banco de Olhos, mas sua qualidade pode variar, sendo necessário adelgaçamento do tecido para evitar desnivelamento no limbo corneal. ${ }^{(18)}$ Estes tecidos, às vezes são conservados em glicerina ou álcool, que não são completamente virucidas e poderiam teoricamente transmitir doenças infecciosas. ${ }^{(18,19)}$

A dura-mater foi utilizada em cirurgia plástica ocular para o revestimento de implantes orbitais e em outras especialidades cirúrgicas. As vantagens deste tecido são: resistência tecidual, flexibilidade, biocompatibilidade e eventual substituição pelo tecido conjuntivo do hospedeiro. ${ }^{(19)}$ Entretanto, a preocupação aumentou com a utilização da dura-mater processada de cadáveres porque a doença de Creutzfeldt-Jacob (DCJ) poderia estar associada ao seu uso. ${ }^{(20)}$

O enxerto dérmico de espessura parcial por ser autólogo não apresenta antigenicidade, e pode integrar e reepitelizar em uma superfície avascular, não sendo necessário o recobrimento conjuntival. Além disso são flexíveis, com boa resistência tensional, de fácil manuseio e boa moldagem na área da enxertia. ${ }^{(14)}$

O enxerto autólogo de cartilagem auricular não apresenta antigenicidade, porém é um tecido difícil de manusear, pois não é flexível e rompe com facilidade. Além disso, a moldagem no leito receptor pode ser comprometida devido à espessura e convexidade irregular. $^{(16)}$

O enxerto de periósteo autólogo não exibe atividade osteogênica. As suas principais vantagens são: a ausência de antigenicidade, boa integração com os tecidos oculares, boa resistência e fácil manuseio. ${ }^{(17)}$

O pericárdio humano processado fornece um apoio que promove a epitelização. Apresenta as seguintes vantagens: custo baixo, material estéril, prazo de validade longo e fácil manuseio. ${ }^{(15)} \mathrm{O}$ pericárdio processado tem sido empregado nos casos de pterígio recidivado, mas não há referência quanto ao seu uso nos casos de úlceras esclerais pós-betaterapia. ${ }^{(21)}$

O presente estudo demonstrou que a esclera autóloga delaminada apresenta a melhor compatibilidade tecidual, não sofrendo reação imunológica e reabsorção. Além disso, este tecido escleral apresenta grande resistência tensional, pouca distensibilidade e grande flexibilidade. É de fácil manuseio e de excelente moldagem na área receptora, sendo um material vanta- 
joso quando comparado ao periósteo autólogo, esclera e dura-mater homólogas.

Uma grande vantagem da presente técnica é que a mesma via conjuntival de preparação do leito receptor serve para a colheita da esclera delaminada. Quando, por exemplo, se usa o enxerto de periósteo pré-tibial ou cartilagem auricular tem-se um outro sítio cirúrgico.

A principal vantagem do atual procedimento, no entanto, é o emprego do mesmo tecido escleral autólogo e exatamente do mesmo padrão histológico que foi perdido durante a evolução da úlcera.

Este aspecto, de se abandonar a utilização de tecido homólogo, ou seja, de outro indivíduo, é absolutamente desejável. Assim, não se tem qualquer risco de transmissão de agentes microbianos, vírus ou prions. Além disso, evita-se a exigência de alguns hospitais, que só permitem a cirugia após a liberação do tecido homólogo por parte da sua "Comissão de Transplantes de Orgãos".

A presente técnica, dadas todas suas vantagens, certamente trará enormes benefícios aos pacientes portadores de úlceras esclerais profundas que necessitem tratamento cirúrgico. Demonstra que o emprego da esclera delaminada autóloga para o tratamento das úlceras esclerais profundas pós-cirurgia de pterígio associada com betaterapia é preferível em relação a outras técnicas utilizadas anteriormente.

\section{REFERÊNCIAS}

1. Tarr KH, Constable IJ. Late complications of pterygium treatment. Br J Ophthalmol.1980;64(7):496-505.

2. Green MO, Brannen AL. Hyperbaric oxygen therapy for betaradiation-induced scleral necrosis. Ophthalmology. 1995;102(7):1038-41.

3. Wilder RB, Buatti JM, Kittelson JM, Shimm DS, Harari PM, Rogoff EE, Cassady JR. Pterygium treated with excision and postoperative beta irradiation. Int $\mathrm{J}$ Radiat Oncol Biol Phys. 1992;23(3):533-7.

4. Walter WL. Another look at pterygium surgery with postoperative beta radiation. Ophthal Plast Reconstr Surg. 1994;10(4):247-52.

5. MacKenzie FD, Hist LW, Kynaston B, Bain C. Recurrence rate and complications after beta irradiation for pterygia. Ophthalmology. 1991;98(12):1776-80; discussion 1781.

6. Samahá JT, Schellini SA, Sakamoto RH, Padovani CR. Tratamento do pterígio recidivado por transplante autólogo de conjuntiva. Arq Bras Oftalmol. 2002;65(4):415-8.
7. Kenyon KR, Wagoner MD, Hettinger ME. Conjunctival autograft transplantation for advanced and recurrent pterygium. Ophthalmology. 1985;92(11):1461-70.

8. Matayoshi S, Romano SML, Prado Júnior J, Alves MR. Tratamento cirúrgico da necrose de esclera após exérese de pterígio e betaterapia. Arq Bras Oftalmol. 1994;57(3):185-6, 189.

9. Duke-Elder S. Diseases of the retina. In: Duke-Elder S, editor. System of ophthalmology. St Louis: Mosby; 1967. Vol. 10.

10. Dusenbery KE, Alul IH, Holland EJ, Khan FM, Levitt SH. Beta irradiation of recurrent pterygia: results and complications. Int J Radiat Oncol Biol Phys. 1992;24(2):315-20.

11. Ti SE, Tan DT. Tectonic corneal lamellar grafting for severe scleral melting after pterygium surgery. Ophthalmology. 2003;110(6):1126-36.

12. Au Eong KG, Tseng PS, Lim AS. Scleral necrosis and infection 15 years following pterygium excision. Singapore Med J. 1995;36(2):232-4.

13. Enzenauer RW, Enzenauer RJ, Reddy VB, Cornell FM, West S. Treatment of scleromalacia perforans with dura mater grafting. Ophthalmic Surg. 1992;23(12):829-32.

14. Mauriello JA Jr, Fiore PM, Pokorny KS, Cinotti DJ. Use of splitthickness dermal graft in the surgical treatment of corneal and scleral defects. Am J Ophthalmol. 1988;105(3):244-7.

15. Schein OD. The use of processed pericardial tissue in anterior ocular segment reconstruction. Am J Ophthalmol. 1998;125(4):549-52.

16. Hellein R. Radio necrosis of the sclera - treated with auricula cartilage graft. Aust J Ophthalmol. 1976;4(2):104.

17. Matayoshi S, Alves MR, Araf D. Periósteo autógeno no tratamento da necrose após exérese de pterígio e betaterapia. Arq Bras Oftalmol. 1996;59(3):251-4.

18. Smith MF, Doyle JW, Ticrney JW Jr. A comparison of glaucoma drainage implant tube coverage. J Glaucoma. 2002;11(2):143-7.

19. John T, John OC, Carey RB. In vitro study of bacterial adherence to processed dura mater, processed pericardium, pericardium in saline, and human sclera. J Cataract Refract Surg. 2003;29(2):371-8

20. Thadani V, Penar PL, Partington J, Kalb R, Janssen R, Schonberger LB, et al. Creutzfeldt-Jacob disease probably acquired from a cadaveric dura mater graft. Case report. J Neurosurg. 1988;69(5):766-9. Comment in J Neurosurg. 1989;71(6):954-5.

21. Alvarenga LS, de Sousa LB, de Freitas D, Mannis MJ. Efficacy and safety of recurrent pterygium surgery using human processed pericardium. Cornea. 2002;21(6):542-5.

\author{
Endereço para correspondência: \\ Eurípedes da Mota Moura \\ Rua Pio XI, no 1181 \\ CEP 05060-001 - Alto da Lapa - São Paulo (SP) , Brasil \\ Fone/Fax: (11) 3832-2173 \\ E-mail:euripedesmoura@uol.com.br
}

